\title{
RECONSTRUCCIÓN Y ACTIVACIÓN DEL PATRIMONIO ARTÍSTICO CON TECNOLOGÍA AUDIOVISUAL. EXPERIENCIA DE TAÜLL 1123
}

\section{Santos M. Mateos-Rusillo y Arnau Gifreu-Castells}
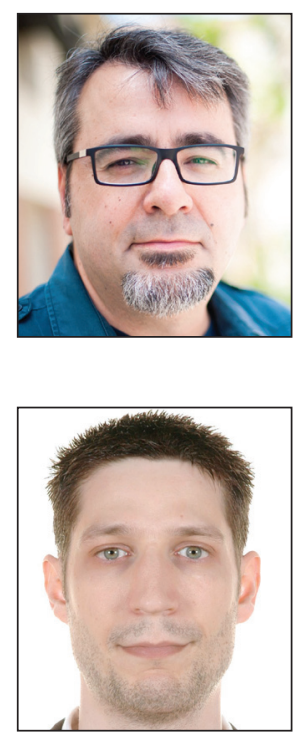

\section{Resumen}

Los museos han retirado obras o conjuntos artísticos de los lugares para los que fueron creados, con la misión de preservar el patrimonio artístico mueble. Con el paso del tiempo los gestores de algunos de esos lugares han comenzado a reclamar su restitución, conscientes de la significación que muchas de esas piezas poseen actualmente. Ante esa petición, algunas instituciones y museos han dado respuesta a esas solicitudes mediante copias de las obras originales. Si tradicionalmente esas réplicas se realizaban de forma artesanal, ahora se utilizan recursos digitales, como la tecnología audiovisual. El proyecto Taüll 1123 (Lleida, España) es una muestra de la utilización de estas nuevas herramientas al servicio del patrimonio artístico y sus visitantes.

\section{Palabras clave}

Patrimonio artístico, Museos, Humanidades digitales, Tecnología audiovisual, Reconstrucción virtual, Video mapping, Activación, Difusión cultural, Taüll 1123.

\section{Title: Reconstruction and activation of artistic heritage using audiovisual technology. Experience of} TaüII 1123

\begin{abstract}
With the aim of preserving artistic heritage, museums have typically removed paintings and furniture from the places they were created for. Over the decades, the curators of these places have begun to request that these artistic works be returned, conscious of the significance that many of these works now have. Some institutions and museums have responded to these requests by providing copies of the original works. Although traditionally these copies were handmade, digital resources, such as audiovisual technology, are now being used. The Taüll 1123 project (Lleida, Spain) is an example of the use of these new tools for the benefit of artistic heritage and of modern visitors.
\end{abstract}

\section{Keywords}

Artistic heritage, Museums, Digital humanities, Audiovisual technology, Virtual reconstruction, Video mapping, Activation, Cultural dissemination, Taüll 1123.

Mateos-Rusillo, Santos M.; Gifreu-Castells, Arnau (2014). "Reconstrucción y activación del patrimonio artístico con tecnología audiovisual. Experiencia de Taüll 1123”. El profesional de la información, septiembre-octubre, v. 23, n. 5, pp. 527-533. 
El pasmoso crecimiento de nuestros medios,

la flexibilidad y precisión que éstos alcanzan,

y las ideas y costumbres que introducen, nos garantizan cambios próximos y muy hondos en la antigua industria de lo Bello

Paul Valéry, La conquista de la ubicuidad, 1928

\section{Introducción}

Durante la primera década del presente siglo The digital humanities manifesto 2.0 (UCLA, 2009) puso de relieve que las herramientas, técnicas y medios digitales han alterado la producción y difusión del conocimiento en las artes y las ciencias sociales y humanas.

Con el inicio de la revolución digital, una serie de profundas transformaciones afectaron a las humanidades y al arte en particular. La transformación vinculada al avance tecnológico y científico no es una novedad en la historia de estas manifestaciones humanas, pues la vinculación con los avances técnicos es algo que siempre las ha acompañado. Si en la pintura del siglo XV la tecnología punta eran los pinceles de pelo de turón y la técnica del óleo, en la del siglo XXI lo son el ratón y el píxel.

Su impacto ha sido tan importante que museólogos como Mark Jones, director del Victoria and Albert Museum de Londres, consideran las nuevas tecnologías tan relevantes para la accesibilidad y la comprensión de los objetos conservados por los museos como lo fue para los textos la invención de los tipos móviles en el siglo XV (Jones, 2010, p. 135).

Después de una primera oleada tecnológica que primaba lo cuantitativo, desde hace unos años las humanidades digitales se encuentran en una fase cualitativa

Después de una primera oleada tecnológica que primaba lo cuantitativo, desde hace unos años las humanidades digitales se encuentran en una fase cualitativa: ahora se están aprovechando buena parte de las posibilidades del mundo digital. Si antes 'bastaba' con disponer en internet de una reproducción de Las meninas de Velázquez, ahora se ponen a disposición de los internautas reproducciones en muy alta resolución que permiten visionar detalles imposibles de captar por el ojo humano delante mismo de la obra en cuestión (Mateos-Rusillo, 2010, p. 118).

La tecnología audiovisual aporta múltiples bondades para la creación de réplicas de obras de arte. En este artículo nos centramos en el análisis de las réplicas realizadas con tecnología audiovisual con un objetivo patrimonial concreto: la reconstrucción de obras de arte perdidas o conservadas en museos y por tanto deslocalizadas del lugar para el que fueron creadas.

\section{La obra de arte: original y copia}

Desde la época clásica, la obra de arte ha sido siempre reproducida (Benjamin, 2008). En la Antigua Roma se realiza- ron copias en mármol de las reputadas esculturas griegas de bronce, que en muchos casos son las que han llegado hasta nuestros días y no sus originales. Basta citar los famosos Discóbolo de Mirón y Doríforo de Policleto.

A partir de la Edad media, a los métodos artísticos de reproducción se unieron poco a poco técnicas de estampación mecánica como la xilografía, el grabado o la litografía, que ya permiten una cierta ubicuidad de la obra de arte. Las cosas cambiaron sustancialmente en el siglo XIX, con la aparición de técnicas modernas de reproducción como la fotografía o el cinematógrafo. Estas artes mecánicas no sólo aumentan la capacidad viajera del patrimonio artístico sino que además ellas mismas se convierten en nuevas técnicas de producción artística, generando un tipo de arte no aurático ${ }^{1}$ basado en la multiplicidad de ejemplares (Carroll, 2002, pp. 155-212; Pouivet, 2003, pp. 21-64; Benjamin, 2008).

\section{Hoy día la copia de una obra de arte pue- de tener tanto o más valor que el propio original}

Hasta ese momento el conocimiento sobre una obra de arte se limitaba a dos posibilidades: su observación directa allí donde se encontrase o mediante reproducciones artísticas o mecánicas. Con la llegada de la revolución digital durante las últimas décadas del siglo $\mathrm{XX}$, el patrimonio artístico ha alcanzado un poder máximo de difusión.

Gracias al aumento considerable de copias y a su facilidad de circulación, se ha pasado de la escasez a la abundancia. Como ya pronosticaba Paul Valéry (1999, p. 131) en 1928, con un simple clic podemos alimentarnos con nuestras pinturas, libros, películas o canciones favoritas, con la misma facilidad con la que el agua, el gas o la corriente eléctrica atienden nuestras necesidades con sólo girar el grifo o pulsar el interruptor de nuestra vivienda.

\subsection{La copia como necesidad de los museos y posibi- lidades para producirlas}

Hay dos grandes causas de la realización de copias por museos: una endógena y otra exógena a la obra de arte.

La endógena se basa en la propia materialidad de la obra de arte, en su aura, utilizando el concepto benjaminiano (Benjamin, 1936, 2008). Atendiendo a esta dimensión, un museo puede optar por la realización de una copia para asegurar su integridad o para restituirla en el lugar para el que fue creada.

La segunda, de tipo exógeno, responde a todo aquello que puede proyectar la obra de arte, ya sea desde el punto de vista educativo, cultural o identitario.

Hay dos posibilidades para realizar una réplica: la artística/ artesanal y la tecnológica. Ante un mismo reto podemos ver esa doble posibilidad sirviéndonos del caso de las Cuevas de Altamira (Santillana del Mar, Cantabria) y de Santimamiñe (Cortézubi, Vizcaya). La pregunta clave sería: ¿cómo asegurar la conservación de la pintura rupestre que albergan con su necesaria exposición al público? 
En Altamira se optó por construir una réplica ideal de la cavidad y sus pinturas en época paleolítica (no en su estado actual, sino imitando como pudieron ser entonces), iniciándose el año 1998 el proyecto que desembocaría en la inauguración de la conocida como Neocueva de Altamira. La reproducción de las pinturas y grabados paleolíticos se realizó siguiendo los métodos y materiales utilizados en su momento por los artistas de Altamira. Un ejemplo de réplica artesanal.

A esta solución se contrapone la utilizada a partir de 2005 para la cueva de Santimamiñe. Partiendo de los mismos planteamientos que en Altamira, el conflicto entre uso y preservación se resolvió de forma distinta, utilizando en este caso las TIC, más específicamente la realidad virtual. Gracias a un proyecto de investigación, conservación y difusión (Santimamiñe 2008), se decidió que la mejor opción para dar a conocer la cueva al gran público era la creación de una réplica virtual en 3D (Barrera-Mayo, 2008).

\subsection{Papel de la tecnología audiovisual como herra- mienta de reconstrucción de obras de arte}

La técnica del video mapping (también conocida como projection mapping o realidad aumentada espacial) se basa en la realización de un escaneo digital que reproduce los contornos y formas de un espacio u objeto tridimensional para poder ser modificado virtualmente con cualquier contenido audiovisual. El concepto nació en la década de los años 70 del siglo XX en Estados Unidos y fue descrito como una nueva conciencia que utiliza la tecnología en entornos multimedia a través de pantallas múltiples, performance, realidad virtual, etc., con el propósito de crear eventos artísticos inmersivos (Youngblood, 1970). Más adelante, a nivel académico se le llamaría realidad aumentada espacial (Raskar et al., 1998).

La técnica del video mapping es interesante para reconstruir el patrimonio artístico perdido o deslocalizado, siempre que aúne rigurosidad y espectacularidad

A finales del siglo XX, piezas representativas como Displacements (Michael Naimark, 1980-2005), Corps étranger (Mona Hatoum, 1994), Ebb y Please (Amy Jenkins, 1996), Man She She (Tony Oursler, 1997) y The homeless projection: a proposal for the city of New York (Krzysztof Wodiczko, 1986) han marcado el punto de inflexión y el uso del video mapping se ha extendido a todo tipo de campos y proyectos.

http://www.naimark.net/projects/displacements.html

http://www.youtube.com/watch?v=QsciOWAd_Lk

http://www.amyjenkins.net/videos/ebb.html http://www.amyjenkins.net/videos/please.htm/

En el campo de los monumentos o espacios patrimoniales, el video mapping se ha puesto de moda en los últimos años para realizar espectáculos de luz y sonido. En Francia es algo que se viene haciendo desde finales del siglo pasado, con una empresa de referencia como Skertzò ${ }^{2}$ y ejemplos tan atractivos como Nuits impressionnistes (2009), De Monet aux pixels (2004-2014) en la Catedral de Rouen, o Rêve de lumières (2008) en el Castillo de Chambord. En España es algo más reciente: Barcelona se convirtió en 2012 en capital española del video mapping, al confluir ese año proyecciones sobre la Casa Batlló, La pedrera o La sagrada familia de Antoni Gaudí.

Más allá de esta interesante utilización de la tecnología audiovisual, en este artículo nos interesa concretamente como herramienta de reconstrucción de obras de arte perdidas total o parcialmente. En este sentido, un caso paradigmático es Amiens, la cathédrale en couleurs. Puesto en marcha en 1999, es un espectáculo audiovisual de 40 minutos que restituye la policromía del siglo XIII que cubría la fachada occidental de la catedral de Amiens (Francia) gracias a una proyección en alta resolución. Se trata de una proyección basada en un trabajo científico previo, que permitió conocer cómo era en realidad la decoración escultórica medieval (Amiens Métropole, 1999).

http://vimeo.com/37098332\#at=17

\section{Estudio de caso: Taüll 1123. La activación del ábside de Sant Climent de Taüll}

Si bien la técnica del video mapping ha sido utilizada para realizar proyecciones sobre monumentos, no es tan frecuente utilizar este recurso tecnológico audiovisual para restaurar virtualmente un espacio perdido o desplazado de un elemento o conjunto patrimonial. De ahí la singularidad del caso seleccionado: Taüll 1123. 


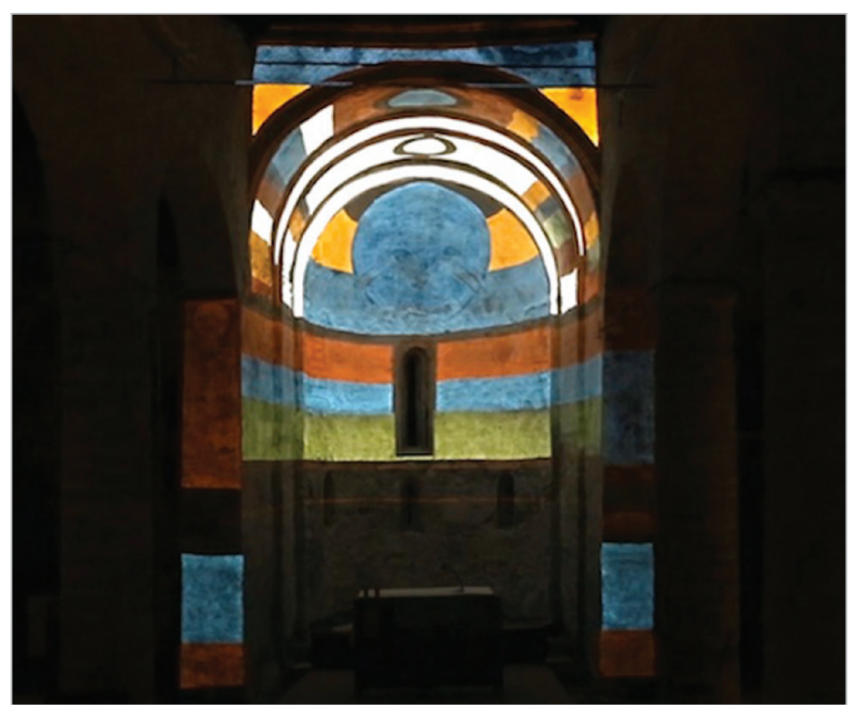

Figura 2. Reconstrucción del color de base en el video mapping

\subsection{Antecedentes}

En nuestro país la falta de valoración del arte románico durante el siglo XIX provocó un peligroso abandono que facilitó su degradación, desaparición, expolio o salida hacia el extranjero. Las cosas comenzaron a cambiar a finales de ese mismo siglo y principios del XX, cuando instituciones públicas, organizaciones privadas e intelectuales iniciaron su recuperación, estudio y divulgación.

Una de las acciones más espectaculares fue la emprendida en Catalunya por la Junta de Museus entre 1919 y 1923. Para evitar su exportación, se llevó a cabo una campaña de compra y arrancamiento de las principales pinturas murales de las iglesias del Pirineo catalán, que viajarían a Barcelona para formar parte de las colecciones del entonces Museu d'Art i Arqueologia de Barcelona (Camps; Pagès, 1999).

Una de las principales fue la decoración del ábside de la iglesia de Sant Climent de Taüll (La Vall de Boí, Lleida), que incluye uno de los fragmentos más celebres de la pintura románica universal: el Pantocrátor o Cristo en majestad. Desde entonces forma parte de la colección de arte románico del Museu Nacional d'Art de Catalunya (MNAC, Barcelona), integrada por obras de pintura mural y sobre tabla, talla en madera, escultura en piedra y orfebrería de los siglos XI, XII y XIII.

\subsection{Génesis del pro- yecto}

Con el objetivo de continuar la investigación sobre los frescos de Sant Climent de Taüll y restituir una obra tan relevante, se decide retirar la copia artística que había realizado el artista Ramon Millet entre 1959 y 1961.
Aunque en un primer momento se barajó la posibilidad de realizar una copia física acoplada al ábside, finalmente se optó por ir más allá de la simple reconstrucción de la obra de arte, generando una verdadera activación patrimonial gracias a un proyecto que fuese capaz de aunar la preservación del bien, su gestión cultural y la actividad religiosa (Rovira, 2013, pp. 16-17).

Es así como nace Taüll 1123, una experiencia inmersiva que permite al visitante de la iglesia románica de Sant Climent de Taüll conocer detalladamente la decoración pictórica que cubría su ábside central ${ }^{3}$.

\subsection{Descripción del proyecto}

Se inició el 8 de marzo de 2013 y concluyó con su presentación pública el 23 de noviembre del mismo año. Se llevó a cabo en tres fases:

1․ fase

- retirada de la reproducción pictórica de 1961;

- descubrimiento de la pinturas anteriores a 1123;

- recuperación de las capas profundas de la pintura de 1123;

- estudio comparativo de los restos preservados in situ y los conservados en el MNAC;

- restauración y consolidación de la pinturas originales del ábside.

\section{2a fase}

- realización de un modelo virtual del templo para obtener su geometría y textura;

- preparación de la proyección mediante la técnica del video mapping;

- creación del audiovisual y de los efectos sonoros.

3a fase

- musealización del ábside.

Durante la segunda fase, la que interesa aquí, no sólo se restituyen virtualmente los restos pictóricos conservados en Barcelona, sino que se aprovecha para proponer una reconstrucción hipotética del estado original de la decoración pictórica del siglo XII.

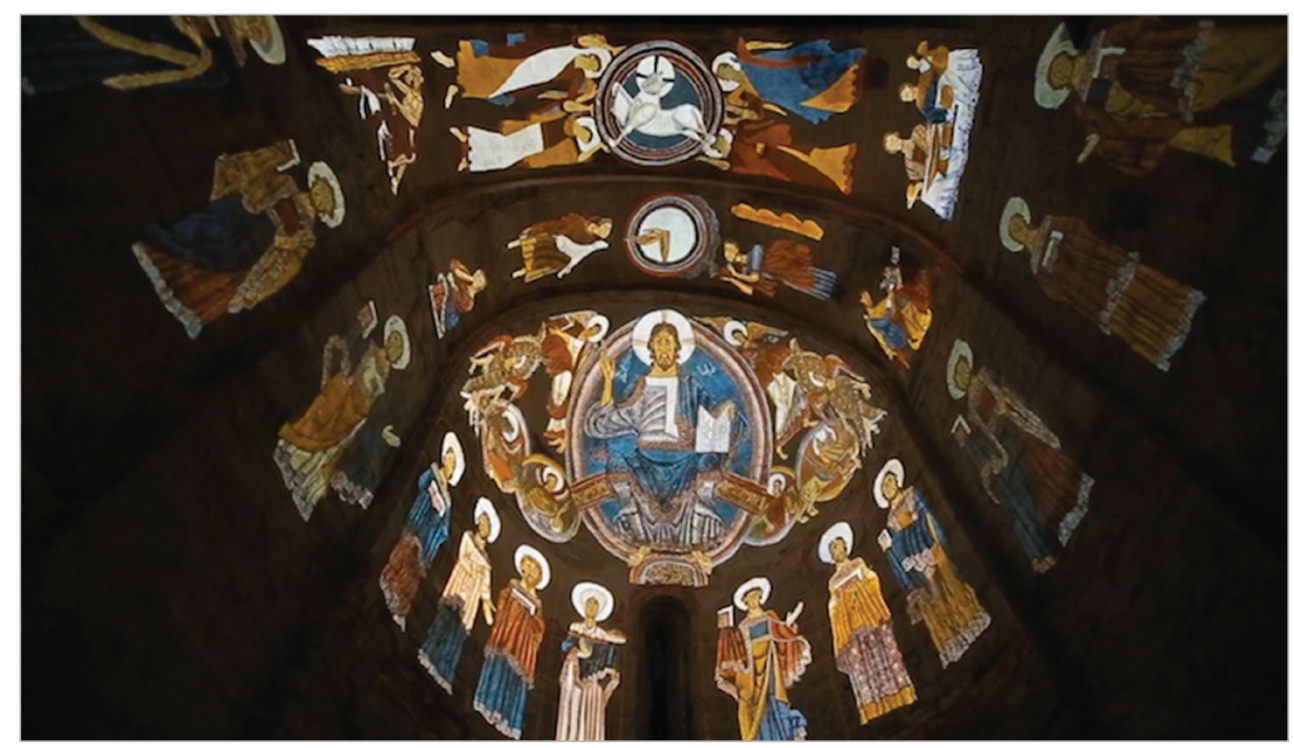

Figura 3. Reconstrucción de las figuras en el video mapping 


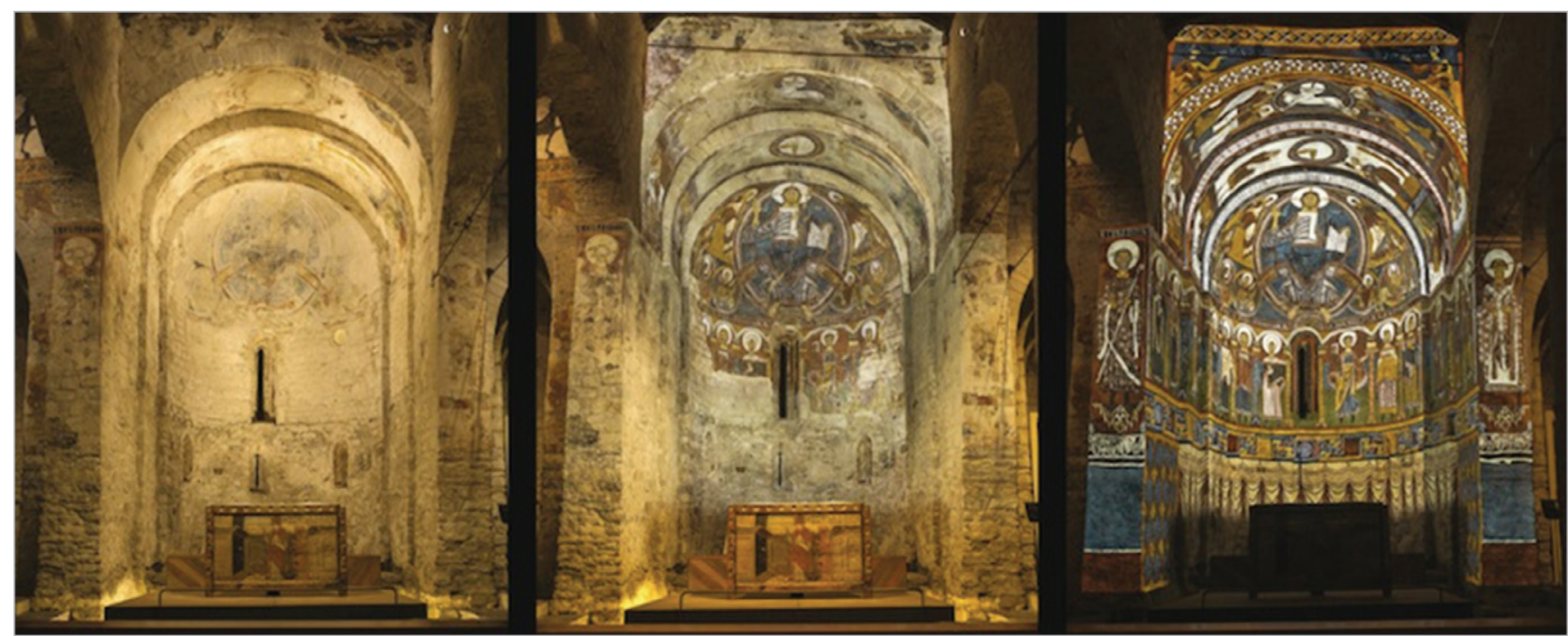

Figura 4. Las tres fases principales de la proyección audiovisual Taüll 1123

El video mapping se activa cada media hora, disparándose sobre el ábside central de la iglesia una proyección de 9 minutos de duración que permite conocer al visitante qué vestigios pictóricos se conservan todavía in situ, cómo era en 1920 cuando se procedió a su arrancamiento y traslado a Barcelona y, retrocediendo en el tiempo 800 años, cómo sería en 1123, año de consagración de las pinturas ${ }^{4}$.

El esmero en la producción del proyecto se comprueba escuchando la música y los efectos sonoros que acompañan a la proyección: la música fue realizada con instrumentos medievales (y posteriormente remasterizada digitalmente para dotarla de una sonoridad contemporánea) y los efectos de sonido se registraron en los alrededores de la propia iglesia.

En la figura 4 se puede observar a la izquierda el ábside de la iglesia con los restos de las pinturas murales románicas originales; en el centro, las pinturas que se conservan actualmente en el MNAC; y a la derecha, las pinturas murales terminadas como lo fueron en el siglo XII. Como comenta Santi Vilanova ${ }^{5}$, compositor de la banda sonora, se trata de un audiovisual que no sólo es riguroso históricamente, sino que también ofrece una narrativa capaz de emocionar al espectador del siglo $\mathrm{XXI}^{6}$.

\subsection{Elementos que complementan el video mapping}

Paralelamente a la proyección en espacios físicos, los museos han aprovechado también la revolución digital para exhibir virtualmente sus piezas y colecciones a través de varios soportes y plataformas, con ejemplos como Monet2010 (2010) y Le Louvre virtual tours (2012).

En esta línea de enriquecer, expandir y complementar la propuesta del video mapping inicial, y a partir de un portal web habilitado a tal efecto, el estudio de caso presentado no sólo cuenta con la utilización de esa técnica, sino también con un tratamiento multimedia de sus partes que se resume en la tabla 1.

http://www.romanicobert. cat/web/guest/taull1123

\section{Conclusiones}

En el caso analizado, el mapping audiovisual es un recurso tecnológico especialmente acertado, ya que permite la conexión entre dos eras de la historia de la comunicación humana. Si en la Edad media la pintura era uno de los principales medios de comunicación, no existe una mejor solución para restituirlas que 
utilizar los recursos propios de nuestra época: la comunicación audiovisual en conjunción con las nuevas tecnologías.

Desde el punto de vista de la mediación cultural, ejemplos como Taüll 1123 facilitan la desacralización de la obra de arte, permitiéndole recuperar su potencial comunicativo al alejarla del moderno culto a la obra de arte (ColoradoCastellary, 1997). Mientras la actual presentación museográfica del original en el MNAC mantiene la característica asepsia divulgativa que caracteriza a los museos de arte, la activación patrimonial de la iglesia de Sant Climent de Taüll permite un acercamiento cultural mucho más enriquecedor.

Para un visitante que busca conocer como debió ser y como se realizó la decoración pictórica del ábside de Taüll, es mucho más provechoso visitar la iglesia que la sala del museo. Por contra, quien quiera confrontarse con los restos conservados, con aquellos pintados en el siglo XII por el anónimo Maestro de Taüll, sin duda debe visitar el museo. Aunque el traslado de una obra de arte pensada para un lugar y con unos objetivos concretos supone una cierta castración de su aura, lo cierto es que en el museo es donde podrá disfrutar de lo que queda de ella.

En este sentido, Taüll 1123 vendría a dar la razón a autores como Douglas Davis, que defiende que en la era de la digitalización de la obra de arte se ha eliminado la ficción que contraponía original y copia, y que la obra de arte, ante el envite de la reproducción, se ha convertido en un camaleón capaz de transferir su poder a la copia (Davis, 1995, p. 381).

Por último, toda la información disponible en internet sobre el propio proyecto y su evolución, en diferentes formatos, permiten difundirlo internacionalmente de forma masiva, facilitando así el conocimiento de la comunidad científica y de los interesados en la aplicación de los avances tecnológicos en el ámbito de los bienes culturales.

\section{Notas}

1. Walter Benjamin Ilamó no auráticas las piezas artísticas que no son originales o que se reproducen muchas veces. Tales piezas no tienen el aura que emana de las obras de arte que son objetos únicos.

2. Para conocer el trabajo de esta empresa pionera y de referencia internacional, se recomienda ver su portal web http://www.skertzo.fr

3. El proyecto, desarrollado por las empresas Burzon Comenge y Playmodes, forma parte del programa cultural Programa de restauración y mejora Románico abierto, puesto en marcha en 2009 gracias a la colaboración entre la Generalitat de Catalunya y la Obra Social "la Caixa".

4. Se puede ver en:

http://vimeo.com/87114296

y en el portal web creado para tal efecto:

http://pantocrator.cat

El proceso de la restauración puede verse en:

https://www.youtube.com/watch?v=FSIKEYeZJSo

https://www.youtube.com/watch?v=-CS_KF4qUbA

Un extenso archivo digital es accesible en el portal web Románico abierto:

http://www.romanicobert.cat/web/guest/taull1123
5. En el vídeo que puede verse en: http://www.youtube.com/watch?v=mYmdSIQvSbs

6. Taüll 1123 ha sido galardonado recientemente con los premios Best of the Web winners en la categoría Rich media de Museums and the Web 2014 y Laus de Oro en la categoría de Visuales de los Premios Laus 2014 de ADG-FAD. http://mw2014. museumsandtheweb.com/bow/taull1123immersive-experience-in-a-world-heritage-site-or-augmentedreality-without-devices

http://www.fad.cat/adg/blog/2014/06/26/els-laus-del2014-los-laus-del-2014

\section{Bibliografía}

Amiens métropole (1999). Amiens, la cathédrale en couleurs. Press pack.

http://www.amiens-cathedrale.fr/download/Press-packamiens-cathedral.pdf

Barrera-Mayo, Sergio (2008). "La tecnología de realidad virtual al servicio de la comunicación y difusión de la Cueva de Santimamiñe". E-rph. Revista electrónica de patrimonio histórico, n. 3. http://www.revistadepatrimonio.es/revistas/numero3/ difusion/experiencias/articulo.php

Benjamin, Walter (1936, 2008). "La obra de arte en la época de su reproductibilidad técnica”. En: Benjamin, Walter. Obras. Libro I, v. 2. Madrid: Abada Editores, pp. 7-47. ISBN: 9788496258617

http://monoskop.org/images/9/99/Benjamin_Walter_La_obra_ de_arte_en_la_epoca_de_su_reproductibilidad_tecnica.pdf

Camps, Jordi; Pagès, Montserrat (1999). "Història dels trasIlats dels absis". Butlleti del Museu Nacional d'Art de Catalunya, n. 3, pp. 17-29.

Carroll, Noël (2002). Una filosofía del arte de masas. Madrid: A. Machado Libros. ISBN: 8477746281

Colorado-Castellary, Arturo (1997). Hipercultura visual. El reto hipermedia en el arte y la educación. Madrid: Editorial Complutense. ISBN: 8489784213

Davis, Douglas (1995). "The work of art in the digital reproduction (an evolving thesis: 1991-1995)". Leonardo, v. 28, n. 5, pp. 381-386.

http://www.jstor.org/stable/1576221

Jones, Mark (2010). "Henry Cole y el desarrollo del Victoria \& Albert Museum como el primer museo dedicado a la accesibilidad y la educación”. En: De-Montebello, Philippe (ed.). El museo: hoy y mañana. Madrid: Museo Nacional del Prado y A. Machado Libros, pp. 121-137. ISBN: 9788484802020

Mateos-Rusillo, Santos M. (2010). "Innovación en la comunicación global del patrimonio cultural: TIC". Revista patrimonio cultural de España, 2010, n. 4, pp. 115-127. http://www.calameo.com/read/000075335d0a70e570294

Pouivet, Roger (2003). L'CEuvre d'art à l'âge de sa mondialisation. Un essai d'ontologie de l'art de masse. Bruselas: Ante Post. ISBN: 2873171901

Raskar, Ramesh; Welch, Greg; Cutts, Matt; Lake, Adam; Stesin, Lev (1998). "The office of the future: a unified approach to image-based modeling and spatially immersive displays". 
Siggraph'98. Procs of the $25^{\text {th }}$ annual conf on computer graphics and interactive techniques, pp. 179-188.

http://web.media.mit.edu/ raskar/UNC/Office/future_office.pdf http://dx.doi.org/10.1145/280814.280861

Rovira, Pere (2013). “Les pintures murals de l'absis de l'església de Sant Climent de Taüll (Vall de Boí)". Rescat. Centre de restauració de béns mobles de la Generalitat de Catalunya, n. 21, pp. 14-17.

http://www20.gencat.cat/docs/msi-cultura/CRBMC/pdf/ Arxiu/RESCAT21.pdf
UCLA Center for Digital Humanities (2009). The digital humanities manifesto 2.0.

http://manifesto.humanities.ucla.edu/2009/05/29/thedigital-humanities-manifesto-20

Valéry, Paul (1999). "La conquista de la ubicuidad". En: Valéry, Paul. Piezas sobre arte. Madrid: Visor, pp. 131-133. ISBN: 8477746001

Youngblood, Gene (1970). Expanded cinema. London: Littlehampton Book Services Ltd. ISBN: 9780289701133

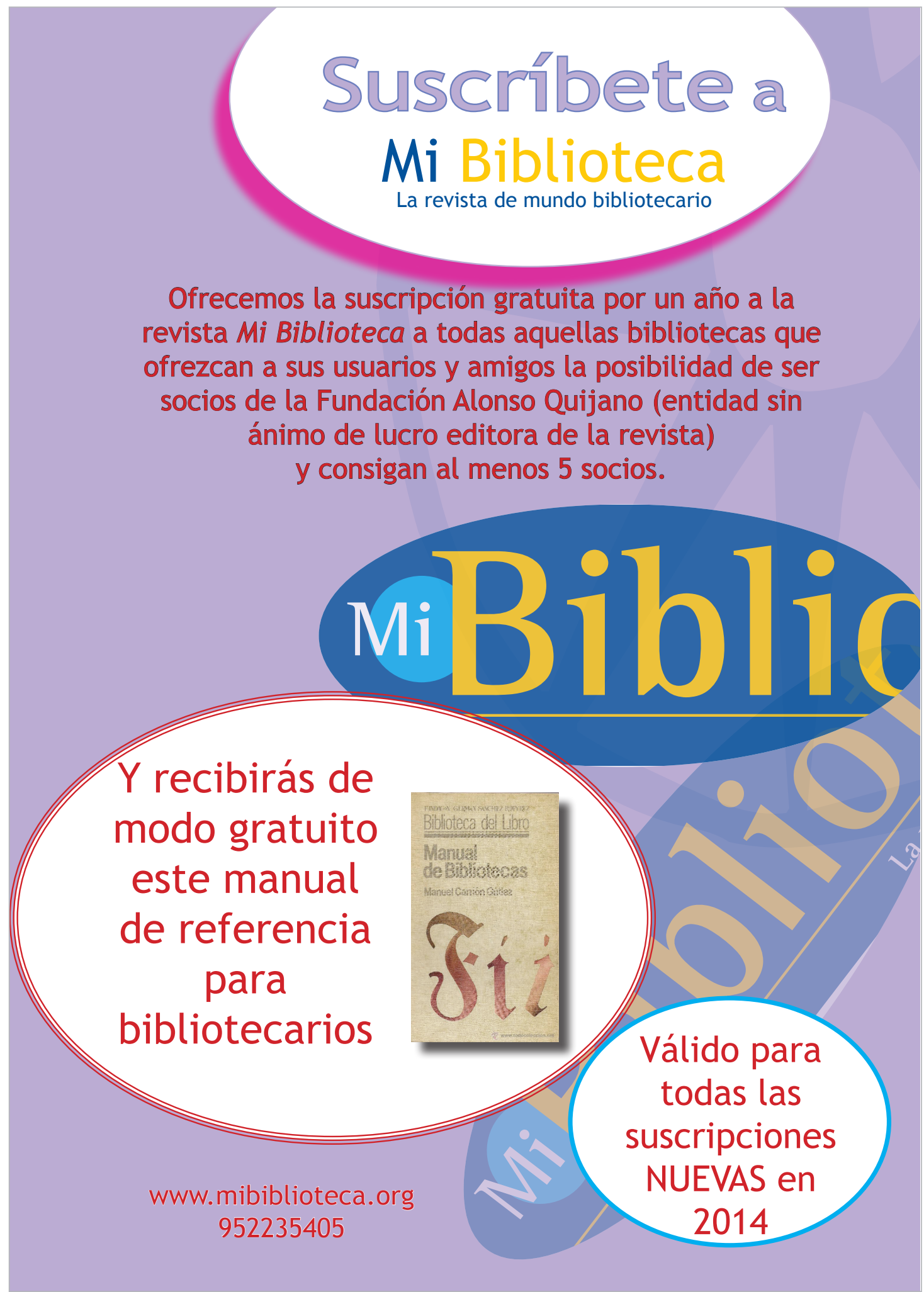

